\title{
Thoughts on Salary Reform in the Digital Age
}

\author{
Tingfang Wang \\ Jianjing Investment \& Consulting Co., Ltd. \\ Hangzhou, Zhejiang, 310004, China
}

\begin{abstract}
This paper mainly analyses the content, necessity and trend of salary change under the background of AI and big data in the current digital economy era. By using literature research and interdisciplinary research methods, this paper explores the salary reform scheme in the digital age from the aspects of the composition of the overall compensation, the external factors affecting the overall compensation, the impact of big data and artificial intelligence on the overall compensation. Five suggestions are put forward to set up personalized rewards for core employees, regard employees as business partners, apply market-based salary system based on big data, adhere to continuous training and development within enterprises, and establish predictive emotional linkage mechanism for employees.
\end{abstract}

Keywords—big data; artificial intelligence; human resources; wage change

\section{INTRODUCTION}

Under the background of the digital economy era in which specialized information systems, big data, artificial intelligence and other sciences and technologies are rising, human resources management has gradually changed from the traditional "six modules" (human resources planning, recruitment, training, performance, salary, labor relations management) to "talent, organization, ideological and cultural" as the core management elements. [1]

With the maturity of artificial algorithm technology, large data has been able to reflect and focus more accurately. With the large data resources of professional artificial algorithm, the field of artificial intelligence has entered all walks of life. Similarly, with the help of AI, big data and professional information system, many human resources "six modules" work, especially repetitive work, such as attendance statistics, personnel statistics, resume selection, training plan performance evaluation, has been gradually replaced by $\mathrm{AI}$ methods and machine methods.[2]After a lot of repetitive work has been replaced by artificial intelligence, human resource workers will not need to do particularly repetitive work, and then adjust the focus of work to the judgment work based on data [3], in order to better serve the human resource work with "talent, organization, ideology and culture" as the core. In this transformation, salary change will run through the whole new human resource management link of "talent, organization, ideology and culture".

\section{COMPOSITION OF OVERALL REMUNERATION}

In the traditional theory of human resource management, salary is usually defined as two concepts: narrow sense and broad sense. In a narrow sense, salary refers to direct income, mainly for wages and salaries, such as basic wages (including post wages), performance wages (various bonuses), other wages (stock options, profit sharing, dividends, etc.), and various management allowances. In a broad sense, salary includes not only salary income directly obtained, but also indirect income such as welfare. Joseph J. Martocchio pointed out that salary includes not only explicit income such as wages and benefits, but also implicit income such as career development and personal growth incentives.[4]

With the development of the times and economy, people's demands are also changing. Compensation has been given a more perfect and comprehensive interpretation. Compensation under the new interpretation has become a part of the overall compensation. In the Mercer Remuneration Report of 2015, the concept of overall remuneration was put forward. Besides salary allowance and other remuneration, employees' remuneration through work includes four parts: career development, comprehensive welfare, work-life balance (see Fig. 1 for details).[5]

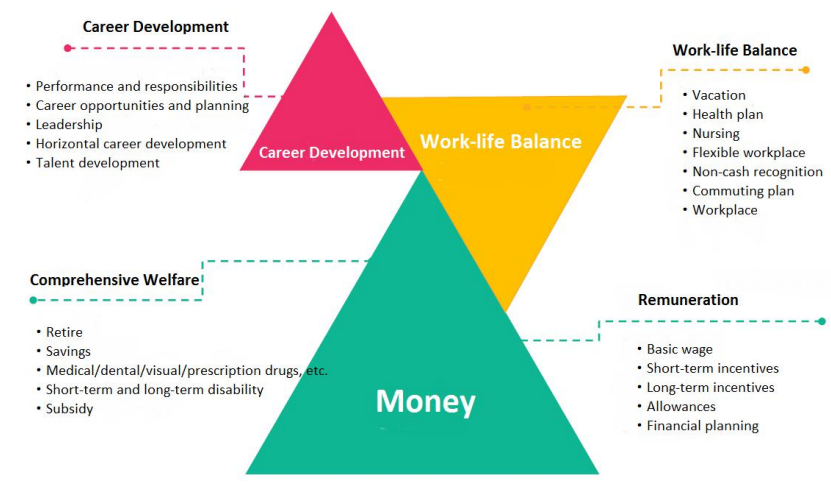

Fig. 1. Overall Compensation Composition Framework

\section{EXTERNAL FACTORS AFFECTING OVERALL COMPENSATION}

The overall salary is mainly influenced by external factors such as macro-economy, society and culture.[4] Under the background of data economy, the main factors are the progress of information technology, the use of big data, the popularization of artificial intelligence, the change of population structure, the rise of labor cost and the formation of cross-border competition in various industries.[1]

1. Progress of information technology: With the popularization of information technology, the formation of global villages, the development of Internet self-Media and the 
improvement of transportation convenience, it is easier for people to understand the global culture and life concept, and then produce the value from the original localization to the complex diversification, which has a great change on the traditional employment form, income composition and other concepts.

2. Use of big data: The application of computers and mobile phones makes information transmission very fast and transparent. The application of various industry websites, specialized software systems, artificial intelligence and the rise of big data make it more convenient and feasible to obtain the contents and standards of the overall salary, and increase the transparency of salary level. At the same time, the development of big data and information technology has increased the flexibility and diversity of office forms, and the time, place and space of office have become diversified.

3. Changes in the demographic structure: According to the United Nations World Population Prospects published in 2019 the phenomenon of population aging will become more and more serious. In 2019, older people aged 65 and over accounted for $1 / 11$ of the global population and are expected to increase to $1 / 6$ by 2050 . At present, China's aging rate is 12 , ranking 57th in the world; it is expected to be 20.7 in 2035 , ranking 44th in the world; 26.1 in 2050, ranking 33rd in the world. [6]As aging has a significant impact on social economy and labor supply, the delay in retirement age has changed the components of the overall salary, such as the proportion of health and medical care of employees in the salary component has gradually increased. According to the United Nations World Population Outlook of 2019, China's labor market is experiencing a decline in the growth rate of the working-age population due to rapid population aging and low birth rate. This makes wage changes inevitable.

4. Background: The Mercer Salary Report of 2015 points out that people of different ages has different demands for the overall salary. Employees in the 1960s (ranging from 46 to 55 years of age) considered job stability as the primary factor; in the 1970s (36-45 years of age) they considered "living for work"; in the 1980s (26-35 years of age), they considered "working for a better life". Most of the respondents said they could not make work the whole of their lives. In the 1990s, employees under the age of 25 considered "doing their own business and doing meaningful work" to be the most important. [5]Therefore, personalized salary design needs have become inevitable.

5. Rising labor costs: According to the minimum wage standards of major cities published by the Ministry of Human Resources and Social Security in 2010-2019, the minimum wage levels of major cities in China have increased substantially in the past decade. The sharp increase in minimum wage and labor cost has gradually weakened the cost advantage of Chinese enterprises. Growth rates in Beijing, Shanghai, Guangzhou, Shenzhen and Jiangsu all exceeded 200 (Fig. 2) .[7]In the case of a sharp increase in human costs, most companies usually reduce the cost of staff training and development to reduce labor costs.

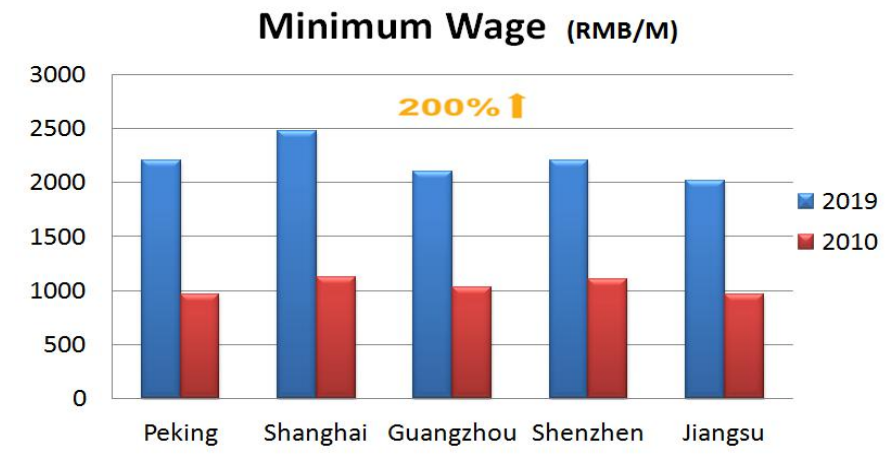

Fig. 2. Wage comparison of five cities in 2010 and 2019

6. Cross-border competition: Due to the explosive growth of the Internet, the boundaries of the industry have not been clear. The development of enterprise complex and the combination of traditional enterprises and the Internet have become a trend. The application of the Internet in various industries has led to the cross-industry demand for talents. The original salary standards and structure applied in a single industry need to be re-set and adjusted.[8]

\section{SALARY REFORM IN "TALENTS, ORGANIZATIONS,} IDEOLOGY AND CULTURE" UNDER THE DIGITAL BACKGROUND

Whether in the World Salary Report in 2015 or Deloitte's Human Capital Trend Sharing in 2019, the trend of more personalized and diversified talent in enterprises is clearly and affirmed. According to Deloitte's Human Capital Trend Sharing Report in 2019, regarding employee value propositions, money or traditional salary bonuses no longer rank first, but the value of work to itself rank first.[9] Therefore, how to increase employee value experience through the adjustment of salary structure and content is very important. On the other hand, whether the salary structure and content can keep pace with the times is also the key to attract and retain talents.[10][11]

In the Deloitte Human Capital Trend Sharing Report in 2019, due to the impact of the digital economy, non-traditional labor force has become the mainstream. How to adjust the employment model to adapt to the change of labor force manifestation is the most important thing. However, organizations have gradually adjusted from the traditional management and control mode to the digital economy mode, inclusive sharing.[9] Different employment modes determine that the salary structure and content need to be adapted to it.

From the perspective of ideology and culture, people born in the 1960s, 1970s, 1980s and 1990s differ greatly in their ideological and cultural requirements and demands. Through the adjustment of salary structure and content, enterprises can transform the traditional staff experience in enterprise culture into human experience and keep pace with the times. 


\section{NECESSITY AND URGENCY OF SALARY REFORM}

Based on the analysis of the factors that influence the wage change due to the development trend of the times, economy and culture, the changes of the overall predictability of compensation are as follows:

Individualization of overall compensation: Because employees' concerns about salary vary according to their age background, companies need to consider the differences of employees' cultural concepts when designing or adjusting salary schemes. According to different perspectives and needs of employees, it has become a trend to increase the investment of flexible welfare plans and set up the overall salary differently.

Compensation marketization: the rapid development of big data and artificial intelligence makes it easier and faster to obtain information from various industries, which will lead to the inevitability of salary transparency and marketization.

Flexible salary method: With the advent of information and technology era, mobile office has changed the traditional working mode of many enterprises, greatly improving the flexibility of office mode and working time. Therefore, the traditional method of salary calculation based on fixed working hours and attendance has changed.

The prominent concern of core employees: Because the employment relationship is no longer the original one-stop concept, core employees are regarded as the key to the success of the company, therefore, the company will pay more attention to the needs of core employees.

\section{SUGGESTIONS ON SALARY REFORM IN THE CONTEXT OF DIGITAL ERA}

In view of the trend of salary change in the digital age, companies can adopt the following five main coping styles: getting personalized incentives for core employees, regarding employees as business partners, applying market-based salaries under big data, continuing training and development (to support employee value proposition), and establishing predictive emotional connection mechanism.

Setting personalized incentives for core employees: With the development of economy, employees from different backgrounds have different definitions and expectations of their career. Most companies regard personalized incentives for core employees as an important part of salary design to attract and retain their core employees. Therefore, more companies provide personalized incentives for core employees, including personalized benefits, personalized career planning and flexible workplace.

Viewing employees as business partners: Under the background of significant changes in the traditional employment model, the traditional management of "fixed pay plus performance pay" has gradually been replaced by a variety of forms of long-term incentives, including employee stock ownership. This is not only limited to Internet companies, but also will actively participate in traditional industries, so that employees can become business partners of the company and develop with the company.
Market Compensation under Big Data: With the popularization and application of Big Data, the structure and content of salary data become more and more transparent. With the cross-border development of enterprises, the company's salary structure and content are no longer limited to the company, the local market and the industry's salary. The salary structure and content will reflect the mode of integration of individualization and standardization under the influence of big data.

Continuous training and development (in support of EVP): Employee value proposition explores the reasons why employees choose to work for their company. Systematic training and sustainable development are planned for employees. As an important part of implicit compensation, this part will help enterprises attract and retain talents and reduce labor costs.

Establishing predictive emotional connection mechanism: Effective emotional connection is an important way for enterprises to transform professional experience into human experience. Through predictive emotional connections, companies can stimulate employees' sense of responsibility, honor and pride, motivate employees to be aggressive, enter the role of owner, link their own development with collective development, and enhance the competitiveness of enterprises to achieve sustainable development.

\section{CONCLUSION}

Under the background of the rapid development of big data and artificial intelligence technology, and based on the three core elements of new human resources management, namely "talent, organization, ideology and culture", under the influence of digital and information technology on talent, organization and ideology and culture, several reform measures, such as personalized overall compensation design, market-oriented salary positioning, implicit incentives and emotional mechanism, are effective ways for enterprises to cope with changes in the external environment.

\section{REFERENCES}

[1] Human Resource Changes brought about by Hanscho's Digital Economy [J], Business News, 2019 (6): 190-191. (In Chinese)

[2] Lan Yanyang. Human Resources Management in the Age of Artificial Intelligence [J], Economic Research Guide, 2018(23):63-64. (In Chinese)

[3] Tu Fengjun. Innovation of Enterprise Management Model in the Age of Big Data [J], China Management Informationization, 2019(6), Vol.22, No.11:79-80. (In Chinese)

[4] Joseph J. Martozio, Strategic Compensation Management [M], 5th edition, Beijing: Renmin University of China Press, 2011. (In Chinese)

[5] MERCER.TRS TOTAL REMUNERATION SURVER, 2015.

[6] United Nations, "World Population Prospects", 2019.

[7] Ministry of Human Resources and Social Security of China. Minimum wage 2010-2019, official website of China Ministry of Human Resources and Social Security. (In Chinese)

[8] H. Dawid, P. Harting, S. van der Hoog, "Manager Remuneration, share buybacks, and firm performance" Industrial and Corporate Change. 2019(3).

[9] Deloitte. Global Human Capital Trend Sharing, Leading Social Enterprises: People-oriented Business Reshaping, 2019. (In Chinese) 
[10] S. John, "Better remuneration needed", The Veterinary record, 2019 (20).
[11] Mercer. 2019 Mercer's employee welfare panorama research report, 2019. (In Chinese) 